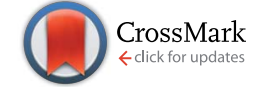

Cite this: RSC Adv., 2017, 7, 1008

Received 11th October 2016 Accepted 19th November 2016

DOI: $10.1039 / c 6 r a 25088 b$

www.rsc.org/advances

\section{A comparative study of physicochemical and functional properties of silver carp myofibrillar protein glycated with glucose and maltodextrin}

\begin{abstract}
Shulai Liu, Peicheng Zhao, Jingjing Zhang, Qiuhong Xu, Yuting Ding and Jianhua Liu*
Myofibrillar protein (Mf) from silver carp (Hypophthalmichthys molitrix) was incubated with glucose and maltodextrin for $0-96 \mathrm{~h}$ at $50{ }^{\circ} \mathrm{C}$ and $75 \%$ relative humidity to obtain glycoconjugates in different periods of the Maillard reaction. Physicochemical properties, including molecular weight, sugars bound to Mf, available amino acid content and FT-IR properties all indicated that glycation occurred successfully. In addition, SDS-PAGE analysis and available amino acids of Maillard reaction productions (MRPs) suggested that glucose reacted more easily with Mf than maltodextrin. Functional properties of MRPs were superior to Mf and reached the highest value at 8-12 h, and then decreased significantly. Heat stability and solubility of $\mathrm{Mf}$-maltodextrin in $0.5 \mathrm{M} \mathrm{NaCl}$ was better than for $\mathrm{Mf}$-glucose, while the solubility in $0.1 \mathrm{M} \mathrm{NaCl}$, and the emulsifying and foaming properties of $\mathrm{Mf}$-glucose were in general better than for Mf-maltodextrin. The variety of saccharides and the process of the Maillard reaction had a great influence on the physicochemical and functional properties of MRPs.
\end{abstract}

\section{Introduction}

Fish protein has high nutritional value, which makes it an essential component of the diet. Myofibrillar protein (Mf) is a primary protein of fish, which can provide favorable functional properties, such as emulsifying properties, gel forming ability, and water-holding capacity. However, some chemical properties and the thermal stability of Mf are worse than for other vertebrates. ${ }^{1}$ When protein denaturation occurs during preparation, processing and storage, the properties of Mf, especially the solubility and emulsifying properties will decrease easily. ${ }^{2}$ Therefore, for the improvement of the additional economic value of fish muscle and the development of fishery, it is particularly important to inhibit or reduce fish protein denaturation, improve its functional properties and then manufacture high quality foodstuffs using fish muscle.

Glycation is the covalent attachment of sugars to available amino groups of proteins to form neoglycoproteins through Amadori rearrangement steps in the Maillard reaction. ${ }^{3}$ Although various available chemical techniques have been developed to prepare synthetic glycoproteins, the production of glycoconjugates between proteins and saccharides using the Maillard reaction has received much attention in recent years. Owing to mild and safe conditions requiring no extraneous chemicals, this reaction is superior to other types of chemical modification for food proteins, and poses a promising

Department of Food Science and Engineering, Ocean College, Zhejiang University of Technology, Hangzhou 310014, P. R. China. E-mail: jhliu@zjut.edu.cn; Fax: +86 571 88320237; Tel: +8657188320237 application for protein modification in the food industry. ${ }^{4}$ Glycation is an effective method to improve the functional properties of fish proteins and even endows them with a novel functionality. ${ }^{5}$ The impact of glycation through the Maillard reaction on food proteins has been widely reported, such as improving the emulsifying properties of fish Mf glycated with alginate oligosaccharides, ${ }^{6}$ raising the solubility of carp Mf conjugated with ribose, ${ }^{7}$ increasing the heat stability of carp Mf glycated with dextran, ${ }^{8}$ enhancing the antioxidant effect of chicken Mf reacted with glucose and maltose, ${ }^{9}$ and improving the gel properties by glycation with konjac glucomannan. ${ }^{10}$ However, these research efforts paid less attention to the impact of the structure and molecular weight of saccharides, and the understanding of the relationships between the types of saccharides and functional properties of glycated Mf is seldom reported.

Glucose, a monosaccharide with small molecular weight, and maltodextrin (DE 20), a polysaccharide with a complex structure and large molecular weight, were chosen as sugar donors in the present study. Myofibrillar protein of silver carp (Hypophthalmichthys molitrix) was used to prepare glycoconjugates through the Maillard reaction, with glucose and maltodextrin, respectively. The aim of this research is to evaluate the changes in the physicochemical and functional properties of the MRPs. More importantly, due to the differences in structure and molecular weight of glucose and maltodextrin, physicochemical and functional properties of Mf-glucose $(\mathrm{M}-\mathrm{G})$ and $\mathrm{Mf}-$ maltodextrin $(\mathrm{M}-\mathrm{M})$ are compared and discussed in depth. 


\section{Experimental}

\subsection{Materials}

Live silver carp was purchased at the local market in Hangzhou. Tris, sodium dodecyl sulfate (SDS), bovine serum albumin, glucose and maltodextrin (DE 20) were purchased from Sigma Company (St. Louis, MO, USA). The other chemicals were purchased from Hangzhou HuaLin Company (Hangzhou, China).

\subsection{Preparation of myofibrillar protein}

The myofibrillar protein was prepared from the ordinary muscle of a cultured silver carp using the method of Saeki. ${ }^{11}$ Firstly, the fish was hit over head with a stick until it was dead. After that, its head and tail were cut. The viscera, skin and bone of the fish were removed to obtain fresh muscle, and then the red muscle and white muscle were separated. The white muscle was ground with a mincing machine and soaked in three volumes of $0.5 \%$ Triton X-100 (containing $0.05 \mathrm{M} \mathrm{NaCl}$ ) for $10 \mathrm{~min}$, and then the supernatant was decanted. The washed ground meat was then re-immersed in 8 volumes (based on initial muscle weight) of $0.05 \mathrm{M} \mathrm{NaCl}$ and $0.5 \%$ Triton X-100 and homogenized for $2 \mathrm{~min}$ at $20000 \mathrm{rpm}$ using a homogenizer (model F6/10, FLUKO Co. Ltd., Germany). After filtration through cotton gauze to remove impurities, the homogenate was centrifuged at $8000 \mathrm{~g}$ for $10 \mathrm{~min}$ to collect the myofibrils. The precipitate was re-suspended in $0.05 \mathrm{M} \mathrm{NaCl}$ and centrifuged $(8000 \mathrm{~g}, 10 \mathrm{~min})$ four times. The pure myofibrils obtained were filtered through nylon cloth. All operations were carried out at $4{ }^{\circ} \mathrm{C}$.

\subsection{Glycation of myofibrillar protein}

The myofibril and saccharide (maltodextrin and glucose) powders with the weight ratio of $1: 2$ were distributed in $50 \mathrm{mM}$ $\mathrm{NaCl}$. The protein concentration of the mixture was adjusted to $6.0 \mathrm{mg} \mathrm{mL} \mathrm{m}^{-1}$. The mixture was frozen at $-80{ }^{\circ} \mathrm{C}$ and then freeze-dried using a freeze-dryer (FD-1-50, Bo Yikang Co. Ltd., Beijing, China). The lyophilized samples were then immediately stored at $-25{ }^{\circ} \mathrm{C}$ and used within 30 days.

The lyophilized mixture was then incubated at $50{ }^{\circ} \mathrm{C}$ for 0,2 , $5,8,12,24,48,72$ and $96 \mathrm{~h}$ and $75 \%$ relative humidity in an incubator cabinet (RXZ-288A, Jiangnan Co. Ltd., Zhejiang, China). After reaction, the protein powder was immediately dissolved in $0.05 \mathrm{M} \mathrm{KCl}-20 \mathrm{mM}$ PBS (pH 7.4), and centrifuged $\left(10000 \mathrm{~g}, 20 \mathrm{~min}, 4{ }^{\circ} \mathrm{C}\right.$ ) four or five times to remove the unreacted saccharides. The precipitate was collected and freezedried for subsequent experiments and analysis.

\subsection{Electrophoretic analysis}

Sodium-dodecyl-sulphate polyacrylamide gel electrophoresis (SDS-PAGE) was used to measure the molecular weight changes of the Maillard reaction products (MRPs), using 7.5\% separating gel and a 5\% stacking gel. Gels were stained with Coomassie Brilliant Blue R250 and destained with a solution of methanol and acetic acid.

\subsection{Amount of saccharides bound to $\mathrm{Mf}$}

As the unreacted saccharides were removed after glycation, the MRPs were re-dissolved in $0.5 \mathrm{M} \mathrm{NaCl}$ containing $40 \mathrm{mM}$ tris$\mathrm{HCl}$ (pH 7.5). The amount of saccharides bound to Mf was determined by the phenol-sulfuric acid method. ${ }^{12}$ Each value of the binding saccharide to Mf was the mean of three replicates.

\subsection{Available amino acid groups}

The amino acid groups were determined by the ortho-phthaldialdehyde (OPA) method with some modifications. ${ }^{13}$ The OPA reagent was prepared by mixing $50 \mathrm{~mL}$ of $0.1 \mathrm{M}$ sodium borate buffer, $5 \mathrm{~mL}$ of $20 \% \mathrm{SDS}, 80 \mathrm{mg}$ of OPA (dissolved in $2 \mathrm{~mL}$ of methanol) and $20 \mu \mathrm{L}$ of $\beta$-mercaptoethanol in water. The MRPs were dissolved in $40 \mathrm{mM}$ tris- $\mathrm{HCl}(\mathrm{pH} 7.5$ ), obtaining $0.5 \mathrm{M} \mathrm{NaCl}$ and adjusted to $6 \mathrm{mg} \mathrm{mL}^{-1}$. Then, the proteins were precipitated with $7.5 \%$ trichloroacetic acid (at the final concentration) to remove the tris buffer, and re-dissolved in a $50 \mathrm{mM}$ phosphate buffer ( $\mathrm{pH} 7.5)$. The mixed solution $(200 \mu \mathrm{L})$ was added to $4 \mathrm{~mL}$ OPA reagent, and the absorbency was read at $340 \mathrm{~nm}$ within $5 \mathrm{~min}$.

\subsection{Fourier transform infrared spectroscopy (FT-IR)}

The infrared absorption data of Mf and modified Mf were obtained in the range $4000-400 \mathrm{~cm}^{-1}$ in $\mathrm{KBr}$ pellets using a Nicolet spectrophotometer Protege 460 FT-IR at room temperature $\left(20^{\circ} \mathrm{C}\right)$. Twenty individual spectra of 64 scans were recorded for each sample at $4 \mathrm{~cm}^{-1}$ resolution.

\subsection{Solubility in media with different ionic strengths}

The solubility and heat stability of MRPs were measured according to previous methods, with some modifications. ${ }^{\mathbf{1 4}}$ The two types of MRPs were dispersed in $40 \mathrm{mM}$ tris- $\mathrm{HCl}$ ( $\mathrm{pH} 7.5$ ), containing $0.5 \mathrm{M} \mathrm{NaCl}$ or $0.1 \mathrm{M} \mathrm{NaCl}$. The protein concentration was adjusted to $1.0 \mathrm{mg} \mathrm{mL} \mathrm{m}^{-1}$. After being homogenized for $1 \mathrm{~min}$ at $12000 \mathrm{rpm}$, the solution was centrifuged at $5000 \mathrm{~g}$ for $30 \mathrm{~min}$. The protein solubility was expressed as the percentage of protein in the supernatant to the total protein content determined by Coomassie Brilliant Blue G250.

\subsection{Heat stability}

The evaluation of heat stability was based on the solubility of the protein. After centrifugation, the supernatant with $0.5 \mathrm{M}$ $\mathrm{NaCl}$ was heated at $80^{\circ} \mathrm{C}$ for $1 \mathrm{~h}$, and then centrifuged at $5000 \mathrm{~g}$ for $30 \mathrm{~min}$. Heat stability was expressed as the percentage of protein in the supernatant, after being heated at $80{ }^{\circ} \mathrm{C}$, to the protein in the supernatant before being heated.

\subsection{Emulsifying properties}

The method of Pearce et $a l .{ }^{15}$ was used, with some modifications. The MRPs were dissolved in $40 \mathrm{mM}$ tris- $\mathrm{HCl}$ and $0.5 \mathrm{M}$ $\mathrm{NaCl}$ ( $\mathrm{pH} 7.5$ ), respectively, and the protein concentration was $3 \mathrm{mg} \mathrm{mL}{ }^{-1}$. The protein solution $(6.0 \mathrm{~mL})$ was mixed with $2.0 \mathrm{~mL}$ of pure corn oil in centrifuge tubes, and homogenized for $1 \mathrm{~min}$ at $13500 \mathrm{rpm}$ in ice water. Then, $0.3 \mathrm{~mL}$ of the emulsion was immediately taken from the bottom of the tube, 
and diluted with $5.7 \mathrm{~mL}$ of $0.1 \%$ SDS at $25{ }^{\circ} \mathrm{C}$. The turbidity of the emulsion was measured at a wavelength of $500 \mathrm{~nm}$ for evaluating the emulsifying activity, expressed as EA. After that, the emulsion was held for $10 \mathrm{~min}$ at constant temperature. The absorbance of the emulsion after standing was taken for dilution and turbidity measurement, as described above. The emulsifying stability was expressed as

$$
\mathrm{ESI}=A_{0} \times T /\left(A_{0}-A_{\mathrm{t}}\right) .
$$

$A_{0}$ : the absorbance of the emulsion before standing; $A_{\mathrm{t}}$ : the absorbance of the emulsion after standing; $T$ : standing time (10 $\mathrm{min})$.

\subsection{Foaming properties}

The foaming properties of the MRPs were characterized through their foam height and stability measured in a tube, based on the method of Sánchez et al., ${ }^{16}$ with some modifications. The foam formation and the foam stability were determined by optical measurements. The foams were produced with a homogenizer for $2 \mathrm{~min}$ at $17500 \mathrm{rpm}$, in $3 \mathrm{~mL}$ of solution (50 mM Tris- $\mathrm{HCl}-$ $0.5 \mathrm{M} \mathrm{NaCl}, \mathrm{pH} 7.5$ ), which contained $1.5 \%$ protein. The initial height of the solution and the foam height were recorded at intervals of $0,2,10,20$ and $30 \mathrm{~min}$, using a caliper. The foaming capacity ${ }^{\mathbf{1 7}}$ was expressed as the proportion of foam height at 0 min to solution height. The foaming stability (FS) was conveyed by the percentage of foam height at some time to $0 \mathrm{~min}$. The measurement of the height was rapid and accurate to three digits after the decimal point.

\subsection{Statistical analysis}

All experiments were carried out with samples from at least three different lots of MRPs. Statistical analysis on a completely randomized design was performed by SPSS 13.0 for Windows software (SPSS Institute Inc., Cary, NC). Duncan's Multiple Range Test was applied to detect differences of means, and $P<0.05$ was considered to be statistically significant.

\section{Results and discussion}

\subsection{Analysis of SDS-PAGE}

SDS-PAGE patterns of Mf and Mf glycated with glucose and maltodextrin are shown in Fig. 1. As reported, Mf was mainly composed of two myosin heavy chains, each with molecular weight of about $200 \mathrm{kDa}$, actin (about $43 \mathrm{kDa}$ ), tropomyosin (about $36 \mathrm{kDa}$ ) and four myosin light chains (about $25 \mathrm{kDa}$, respectively) (Fig. 1, lane 1). ${ }^{17}$ The SDS-PAGE patterns show the changes in the protein subunits during the glycation process. With the process of glycation, the electrophoretic mobility of the myosin heavy chain and actin decreased slightly. This agrees well with the report by Katayama et al. ${ }^{18}$ about myofibrillar proteins of shellfish glycation with glucose. The cross linking mainly between lysine residues of myofibrillar protein and sugars resulted in the increase of the molecular weight of the myosin heavy chain and actin. Since the mobility of bands in the SDS-PAGE depend on the molecular weight of protein subunits, which became heavier, the electrophoretic mobility of the corresponding bands became slower. In addition, in the early stage of glycation, it could be observed that the distance of the stripes mobility in Fig. 1b was more significant than in Fig. 1a, because of the larger molecular weight of maltodextrin than glucose.

Furthermore, myosin, tropomyosin and actin in both Fig. 1a and $b$, were found to disappear gradually in the later stage of glycation (lane 7, 8 and 9), due to the possible degradation of the main components of myofibrillar proteins. Also, the loss of subunits in Fig. 1a was more serious than in Fig. 1b, probably because maltodextrin would protect Mf from degradation or denaturation to a certain extent.

\subsection{Evaluation of the glycation progress}

The Maillard reaction is the covalent attachment of sugars to available amino acid groups of protein (mainly lysine). With the process of glycation, the saccharides attached to Mf increased, while the available amino acid groups decreased.

As shown in Fig. 2, the rapid loss of available amino acid groups occurred, and after $96 \mathrm{~h}$ of reaction, it decreased to $40 \%$ (Mf-glucose glycoconjugates) and 50\% (Mf-maltodextrin glycoconjugates) of the initial values. These results indicate that the interaction between glucose/maltodextrin and Mf was severe. About half of the available amino acid groups were substituted in Mf by glucose and maltodextrin. This result was similar to Sato et al. ${ }^{19}$ who reported that glycated myofibrillar proteins had a significant decrease in amino acid groups and increase in the saccharide content. Besides, the loss of available

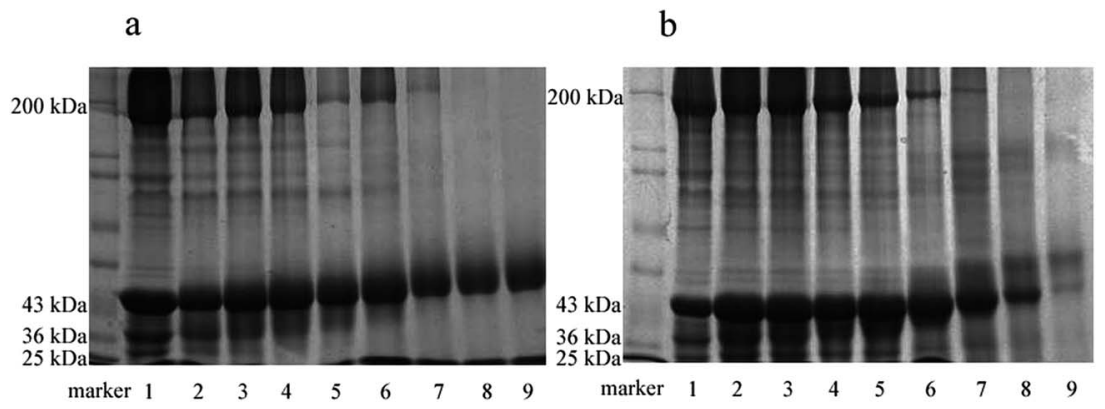

Fig. 1 SDS-PAGE patterns of glycated myofibrillar proteins. (a) Mf-glucose glycoconjugates, (b) Mf-maltodextrin glycoconjugates. Lanes 1, 2, 3, $4,5,6,7,8$ and 9: incubation for $0,2,5,8,12,24,48,72$ and 96 h, respectively. 

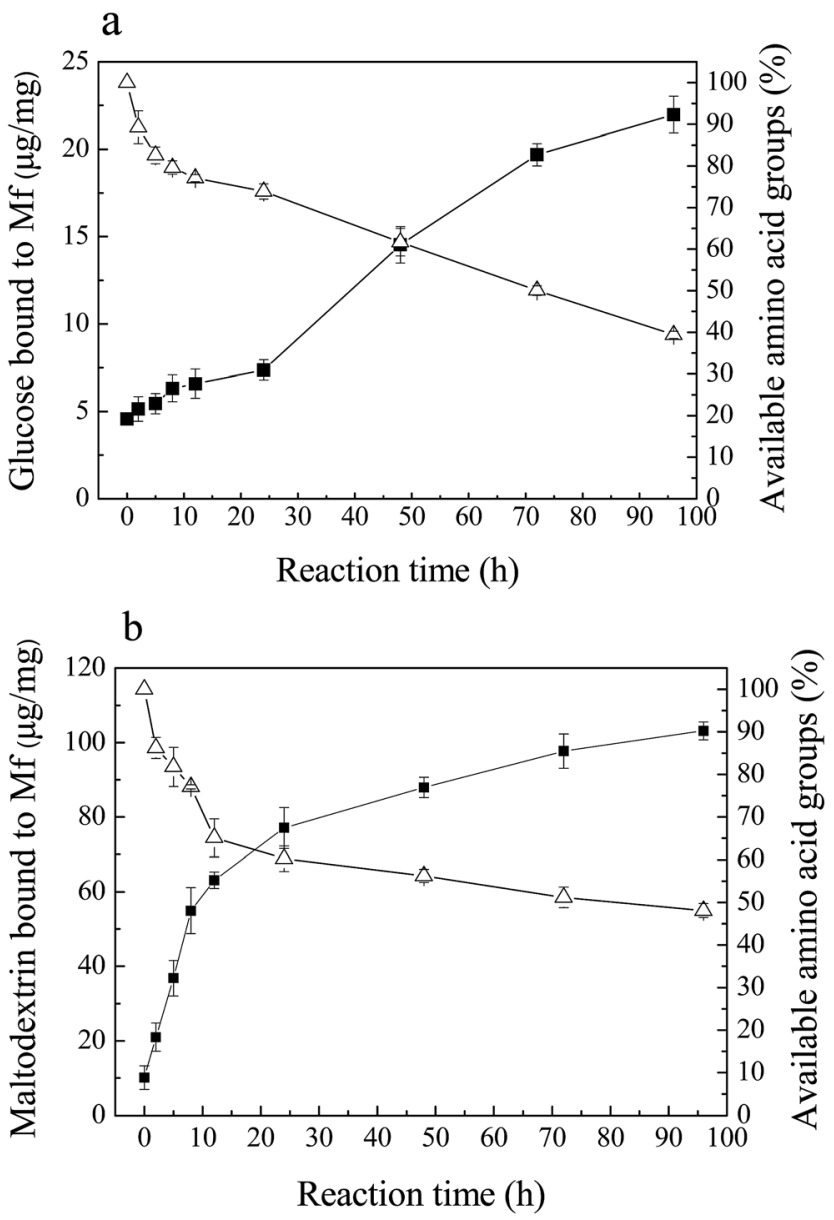

Fig. 2 Amount of saccharides bound to $M f(\square)$, and the decrease in available amino acid groups $(\Delta)$ in Mf during reactions with saccharides for different reaction times. (a) Mf-glucose glycoconjugates, (b) Mfmaltodextrin glycoconjugates.

amino acid groups of Mf-glucose was greater than for maltodextrin; this is because glucose has the smaller molecular weight, leading to a faster reaction with Mf than maltodextrin.

The amount of saccharides bound to Mf increased simultaneously with the loss of the available amino acid groups. The binding glucose and maltodextrin increased markedly during the reaction and reached $22 \mu \mathrm{g} \mathrm{mg}{ }^{-1}$ (Fig. 2a) and $105 \mu \mathrm{g} \mathrm{mg}{ }^{-1}$ (Fig. 2b) after 96 h, respectively. Furthermore, it was observed that the amount of attached maltodextrin was more than glucose, because the molecular weight of maltodextrin is much larger than glucose.

\subsection{FT-IR analysis}

FT-IR spectroscopy is a particularly useful technique for the study of protein-carbohydrate systems ${ }^{20}$ because the chemical fingerprints of proteins and carbohydrates do not overlap significantly in several identifiable regions of the mid-infrared spectrum. $^{21}$

The FT-IR spectra for $\mathrm{Mf}$ and Mf-glucose/maltodextrin mixture incubated in different periods are shown in Fig. 3a and $b$, respectively. The most distinctive spectral features for
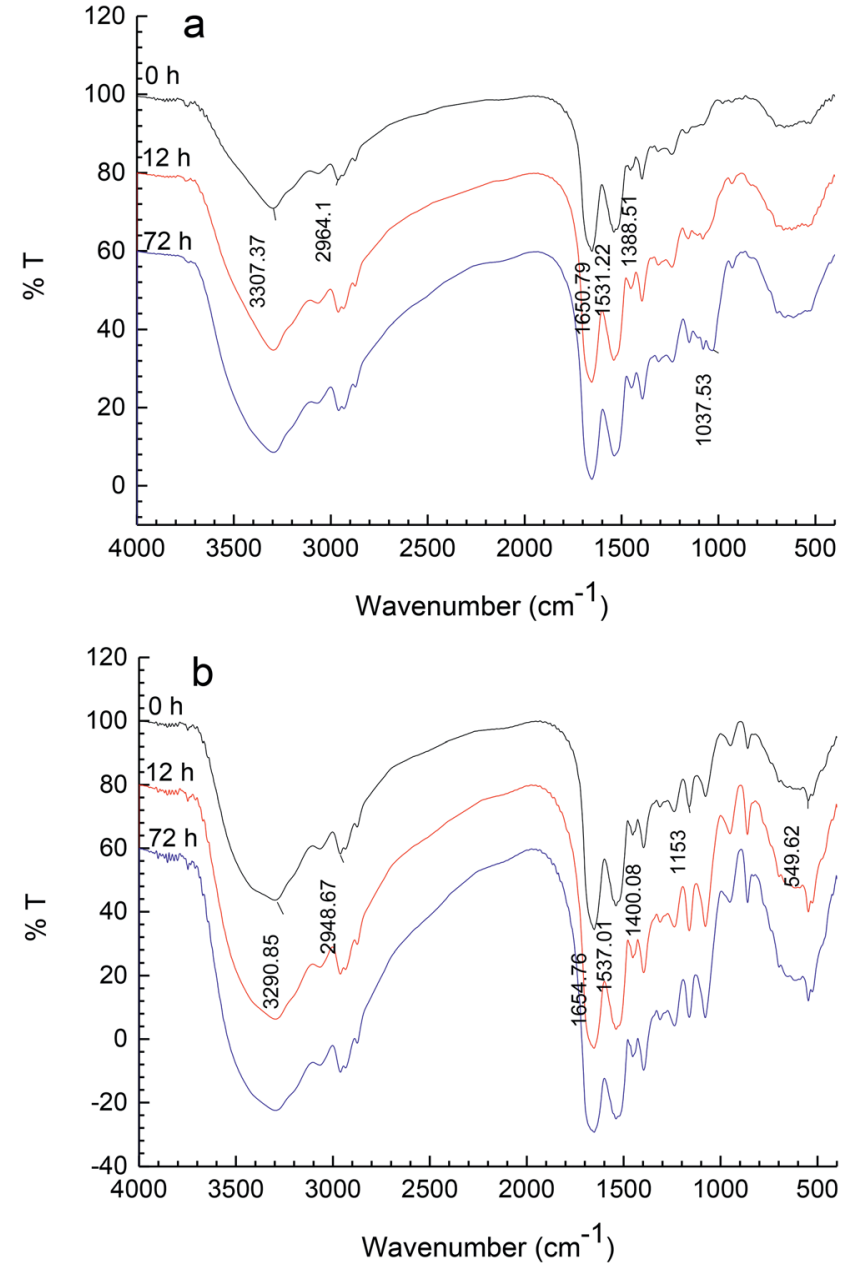

Fig. 3 FT-IR spectra of MRPs. (a) Mf-glucose glycoconjugates, (b) Mfmaltodextrin glycoconjugates.

proteins are the strong amide I and II bands centered at approximately $1650 \mathrm{~cm}^{-1}$ and $1540 \mathrm{~cm}^{-1}$, respectively. ${ }^{22}$ For carbohydrates, a series of overlapping peaks located in the region of $1180-953 \mathrm{~cm}^{-1}$ results from vibration modes such as the stretching of $\mathrm{C}-\mathrm{C}$ and $\mathrm{C}-\mathrm{O}$, and the bending mode of $\mathrm{C}-\mathrm{H}$ bonds. These absorptions are weak in most proteins. In both Fig. $3 a$ and $b$, it was found that the intensities of the peaks in the regions of $1650 \mathrm{~cm}^{-1}$ and $1540 \mathrm{~cm}^{-1}$, ascribed to $\mathrm{C}=\mathrm{O}$ and $\mathrm{C}-\mathrm{N}$ from amide $\mathrm{I}$ and II, increased with the progress of the reaction; this is because functional groups including $\mathrm{NH}_{2}$ may be lost, while the amount of those associated with Maillard products, such as the Amadori compound $(\mathrm{C}=\mathrm{O})$, Schiff base $(\mathrm{C}=\mathrm{N})$, and pyrazines $(\mathrm{C}-\mathrm{N})$, may be increased by the Maillard reaction, as reported by Farhat et al. ${ }^{20}$ In addition, in the spectra of proteins, the amide III band is at $1300-1200 \mathrm{~cm}^{-1}$; this band is very complex and results mainly from $\mathrm{C}-\mathrm{N}$ stretching and $\mathrm{N}-\mathrm{H}$ deformation. ${ }^{23}$

In the spectra of $\mathbf{M}-\mathbf{M}$ or $\mathbf{M}-\mathrm{G}$, it was observed that the absorptions of $\mathrm{C}-\mathrm{OH}$ from $1015 \mathrm{~cm}^{-1}$ to $1200 \mathrm{~cm}^{-1}$ were stronger with the glycation progress, due to the saccharides increasingly attaching to Mf. The introduction of $\mathrm{C}-\mathrm{OH}$ groups in the protein may increase the hydrophilicity of the system. ${ }^{24}$ 
There were obvious differences between $\mathrm{M}-\mathrm{M}$ and $\mathrm{M}-\mathrm{G}$ in the feature region of carbohydrates, because of the appearance of feature absorptions of glucose and maltodextrin.

\subsection{Changes in solubility and heat stability}

Solubility is one of the critical functional properties of proteins, which has great influence on other functionalities. ${ }^{25} \mathrm{Fig}$. 4a and b show the changes in solubility of MRPs in $0.1 \mathrm{M}$ and $0.5 \mathrm{M}$ $\mathrm{NaCl}(\mathrm{pH}$ 7.5) with the progress of glycation. In low ionic strength medium $(0.1 \mathrm{M} \mathrm{NaCl}$, Fig. $4 \mathrm{a})$, the total solubility of $\mathrm{M}-\mathrm{G}$ in $0.1 \mathrm{M} \mathrm{NaCl}$ increased markedly with glycation. It reached a maximum at 8 hours of reaction. Such an increase was not yet observed in the protein with maltodextrin. This result conformed to the description of Saeki and Inoue, ${ }^{26}$ who significantly improved the solubility of $\mathrm{Mf}$ after conjugation with glucose. As described in another report, ${ }^{27}$ proteolysis of $\mathrm{Mf}$ often causes an increase in the solubility of Mf. However, almost no protein degradation was observed at the initial stage of the Maillard reaction, as shown in SDS-PAGE. Therefore, the increase in the total solubility in $0.1 \mathrm{M} \mathrm{NaCl}$ was mainly due to the glycation. This effect may be as a result of covalent linkage to carbohydrates, in which the net charge of the proteins changes and hydrophilic residues are produced. ${ }^{28}$ However, glucose is a reducing saccharide with small molecular weight, which has a faster reaction rate with Mf. Substitution of maltodextrin at the C-4 hydroxyl group of the glucosyl residues makes it less energetically prone to post-Amadori Maillard reactions. ${ }^{29}$ Thus, the enhancement of the solubility of $\mathrm{M}-\mathrm{M}$ was weaker than for M-G. Meanwhile, it can be observed that a marked decrease in the amount of solubilized Mf occurred with further progression of glycation. This result indicated that the thermal denaturation of Mf during the later Maillard reaction had a great influence on the total solubility.

However, in high ionic strength medium $(0.5 \mathrm{M} \mathrm{NaCl}$, Fig. $4 \mathrm{~b}$ ), the solubility of $\mathrm{M}-\mathrm{M}$ and $\mathrm{M}-\mathrm{G}$ had a slight decrease at the early stage of the Maillard reaction and diminished more rapidly later. This depended on the heat denaturation of myofibrillar proteins, and glycation would have little effect on the total solubility in high ionic strength media. Protein is known to be stabilized in the presence of saccharide. ${ }^{30}$ As reported by Nishimura et al. ${ }^{14}$ the difference in protein solubility with a decrease seemed to be caused by a shortage of saccharide as a thermal protectant. In this study, saccharides were only two times the weight of protein, which might be too small to defend Mf. Moreover, the solubility of $\mathrm{M}-\mathrm{M}$ in high ionic strength solution was better than $\mathrm{M}-\mathrm{G}$ in general, because maltodextrin was superior to glucose in inhibiting the protein denaturation during lyophilization and glycation, ${ }^{31}$ which was related to the stereospecific blockade and molecular weight of the carbohydrate.

A marked decrease in solubility in the process of glycation was observed. In addition to higher relative humidity and longer reaction time, lyophilization is a key factor that influences the total solubility, due to the denaturation of proteins. Saeki ${ }^{11}$ reported that, after lyophilization, the solubility of Mf decreased from $86 \%$ to $44 \%$.
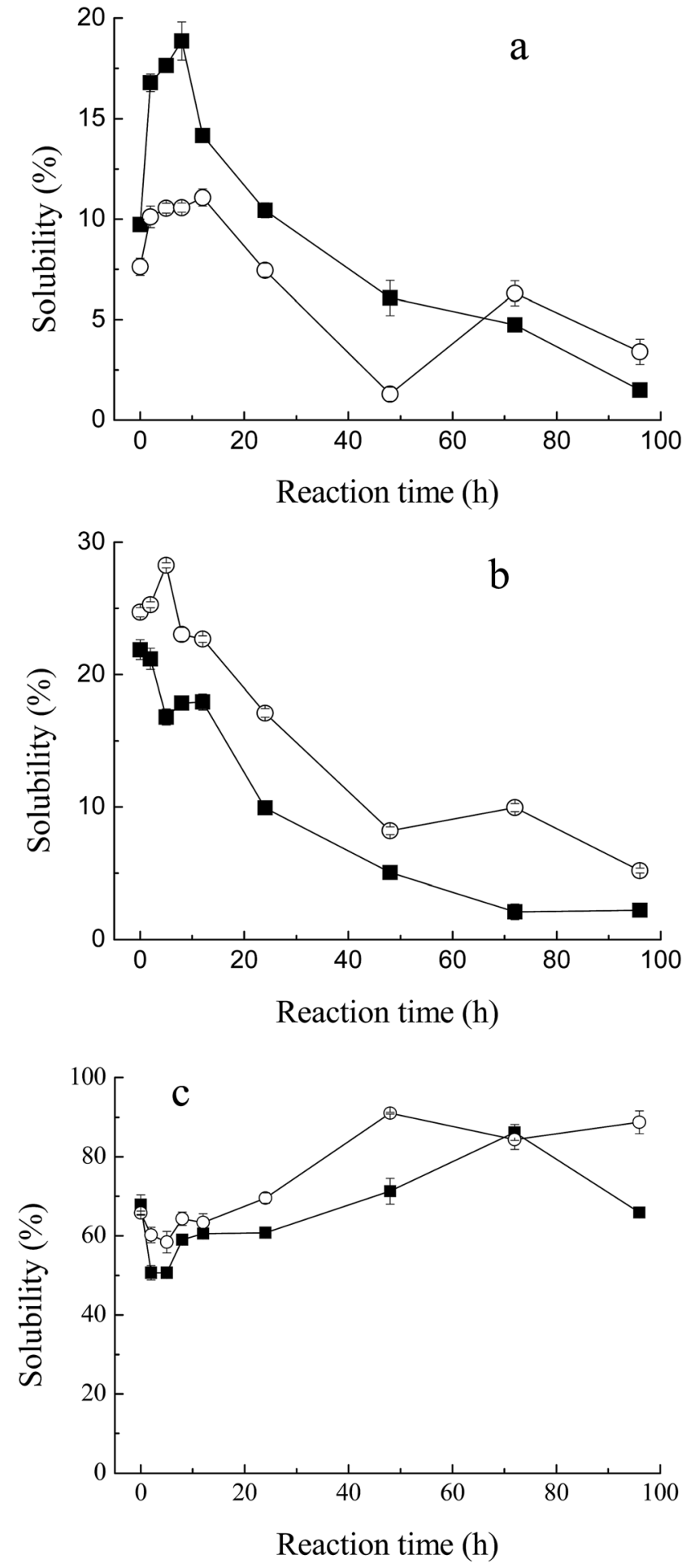

Fig. 4 Change in solubility of myofibrillar protein during glycation with sugars. (a) Low ionic strength medium (0.1 M NaCl, pH 7.5), (b) high ionic strength medium ( $0.5 \mathrm{M} \mathrm{NaCl}, \mathrm{pH} 7.5)$, (c) effect of heat treatment $\left(80{ }^{\circ} \mathrm{C}\right.$ for $1 \mathrm{~h}$ ) on heat stability of MRPs. Lyophilized myofibrillar proteins with glucose $(\mathbf{\square})$, and maltodextrin (C).

As shown in Fig. 4c, Mf itself has a relatively high heat stability at $68 \%$ solubility, when heated at $80^{\circ} \mathrm{C}$ for $1 \mathrm{~h}$. With the process of glycation, the heat stability of MRPs dropped at first, and then rose significantly to $90 \%$ at $48 \mathrm{~h}$ of reaction. As 
described in the solubility of MRPs, saccharides play an important role in protecting proteins from heat denaturation. However, at $2 \mathrm{~h}$ and $5 \mathrm{~h}$ of Maillard reaction, the influence of glycation was weaker than heat, which led to the reduction of heat stability. Simultaneously, with more and more saccharides attached to Mf, its stability against heating apparently improved. Besides, it can be observed that the heat stability of $\mathbf{M}-\mathbf{M}$ was better than $\mathbf{M}-\mathrm{G}$ in general. Enomoto et $a .^{32}$ demonstrated that polysaccharide moieties inhibit the close approach and interaction of protein molecules in either their native or denatured state. Thus, the effect of maltodextrin in protecting Mf against heat is better than that of glucose. This conclusion is in agreement with the results of the solubility of $\mathrm{M}-\mathrm{M}$ and $\mathrm{M}-\mathrm{G}$ in $0.5 \mathrm{M} \mathrm{NaCl}$.

\subsection{Emulsifying properties}

Fig. 5 shows the emulsifying properties of MRPs. Emulsion activity and stability in this study indicate the ability to absorb at the oil/water interface at the end of homogenization, ${ }^{33}$ and
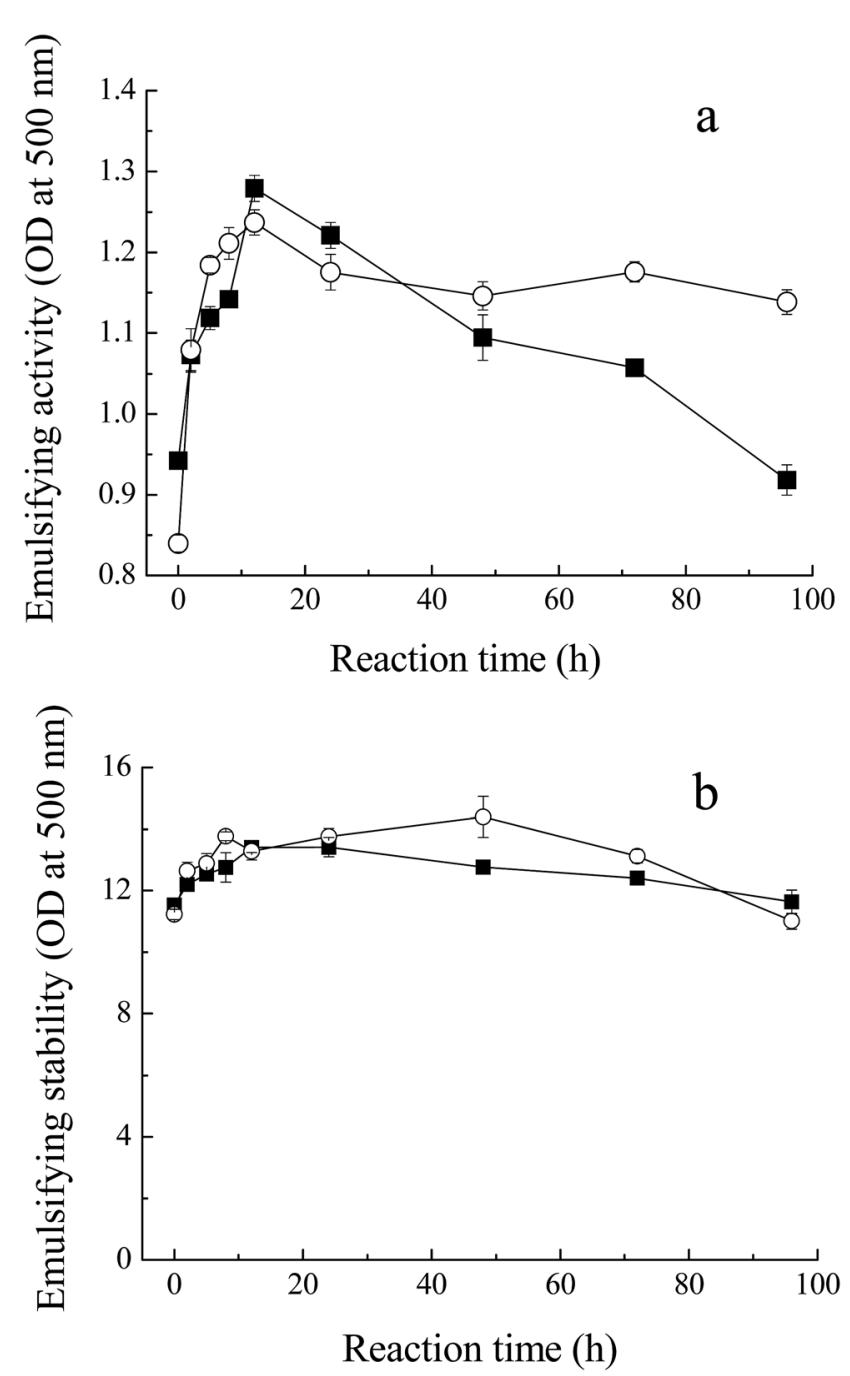

Fig. 5 Emulsifying properties of MRPs. (a) Emulsifying activity of Mf conjugated with sugars, (b) emulsifying stability of glycated Mf. Myofibrillar proteins with glucose ( $\square$ ), and maltodextrin (O). consequently, to stabilize emulsion. With the process of glycation, the turbidity of the emulsion of the glycated Mf increased from 0.9 to 1.3 (OD at $500 \mathrm{~nm}$ ) within $12 \mathrm{~h}$. At the later stage of the Maillard reaction, with the protein polymerization or browning, the emulsion activity decreased to 1.0, due to the loss of the binding spot of the protein for the $\mathrm{O} / \mathrm{W}$ interface. This result was in agreement with the changes in solubility of MRPs. However, the enhancement of emulsion stability was not significant because the ratio of sugar and protein plays a critical role in the mechanism behind the observed increase in emulsifying properties. The increase in steric stabilization may endow greater emulsifying properties to the conjugate.

In addition, unlike the conclusion of Li et al.,${ }^{34}$ who measured the effects of saccharide structure on properties, the difference between $\mathbf{M}-\mathbf{M}$ and $\mathbf{M}-\mathbf{G}$ was not distinct. Former research proposed that branched polysaccharides could improve the emulsifying properties of Maillard conjugates more efficiently and provide more steric hindrance, preventing coalescence of the coated fat droplets. ${ }^{35,36}$ However, maltodextrin has few hydrophobic groups and branches, compared to other polysaccharides. Meanwhile, maltodextrin has the inclusion effect and glucose has a faster reaction with Mf. In conclusion, the emulsifying properties of $\mathbf{M}-\mathbf{M}$ were slightly superior to $\mathrm{M}-\mathrm{G}$.

\subsection{Foaming capacity and stability}

The foaming capacity $^{\mathbf{1 7}}$ and foaming stability (FS) were measured for $\mathrm{M}-\mathrm{M}$ and $\mathrm{M}-\mathrm{G}$ through the height of foaming. As shown in Fig. 6a, the glycated Mf showed significant improvement compared to native $\mathrm{Mf}$ and even reached the highest FC of $80 \%$ at the incubation period of $8 \mathrm{~h}$. The foaming capacity of both $\mathbf{M}-\mathbf{M}$ and $\mathbf{M}-\mathrm{G}$ dropped markedly with further reaction. The glycated proteins may increase the flexibility of the native protein structure, the conformational change, and the protein surface rearrangement, which lead to enhanced protein adsorption at the air-water interface by bubbling. ${ }^{37}$ In addition, Chevalier et $a l .{ }^{38}$ proved that the properties of saccharides were the key factors that influence the foaming properties of glycated Mf. Moreover, protein solubility is the principal condition for proteins to have a good foaming activity, and the variations of FC within the process of the Maillard reaction were the same for solubility. Foaming stability, which was determined by the volume of liquid drained from the foam over time, reached the highest value of $60 \%(\mathrm{M}-\mathrm{G})$ and $40 \%(\mathrm{M}-\mathrm{M})$ at $8-12 \mathrm{~h}$ of reaction, as shown in Fig. $6 \mathrm{~b}$ and c. Moreover, regardless of the phase of foaming disappearance (2, 10, 20 and $30 \mathrm{~min})$, MRPs of $8 \mathrm{~h}$ and $12 \mathrm{~h}$, on the whole, maintained the highest FS. Chevalier et $a .^{38}$ indicated that the modification with sugar improved the foam stability of protein, as a result of the enhancement of solubility, hydration of protein and the amount of protein adsorbed at the air-water interface.

Li et al. ${ }^{39}$ reported that glycated proteins with saccharides of higher molecular weight may increase the foaming properties of MRPs more efficiently. However, in this study, changes in the foaming activity of $\mathrm{M}-\mathrm{M}$ and $\mathrm{M}-\mathrm{G}$ were almost analogous. This may due to the faster reaction of $\mathrm{Mf}$ and glucose, and the special structure of maltodextrin. Glycation of glucose and Mf may 

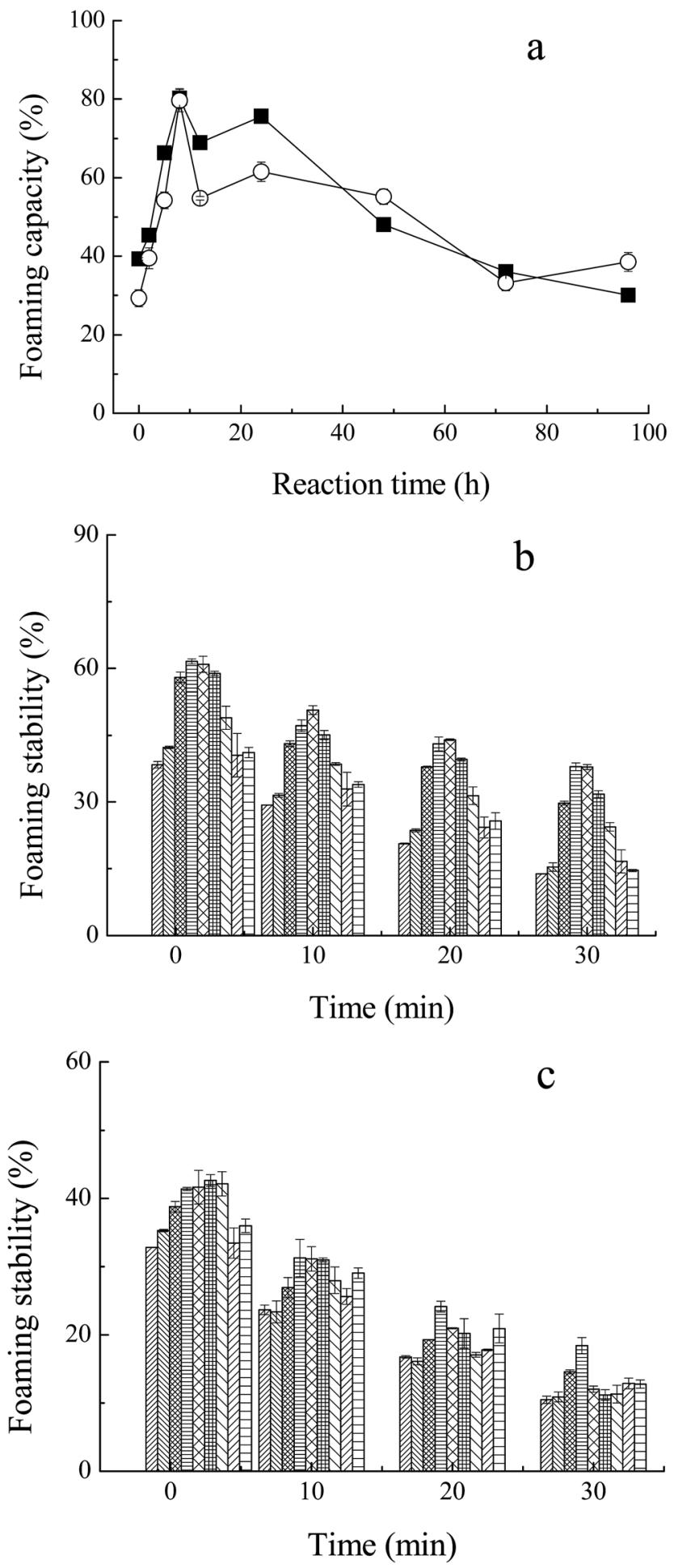

Fig. 6 Foaming properties of MRPs. (a) Foaming capacity of MRPs, (b) foaming stability of Mf conjugated with glucose, (c) foaming stability of Mf conjugated with maltodextrin. Myofibrillar proteins with glucose ( $\square$ ),

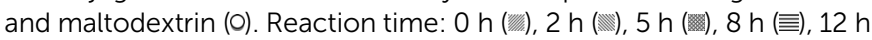

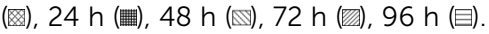

change the surface properties and flexibility of protein to a larger extent, but maltodextrin may contribute to the better protein adsorption at the air-water interface by bubbling. Thus, the foaming capacity of $\mathrm{M}-\mathrm{G}$ was slightly superior to that of $\mathrm{M}-$
M. However, the foaming stability of $\mathrm{M}-\mathrm{G}$ was apparently better than that of $\mathbf{M}-\mathbf{M}$, probably because maltodextrin has a larger steric hindrance than glucose. The larger space structure of the saccharide may have prevented liquid running off the foam, and stabilized the formation of foam, which markedly improved the foaming stability of the MRPs.

\section{Conclusion}

The changes in physicochemical properties of $\mathbf{M}-\mathrm{G}$ and $\mathbf{M}-\mathbf{M}$ indicate that the reaction between $\mathrm{Mf}$ and glucose was faster than Mf and maltodextrin, while the protection of maltodextrin for Mf was better than glucose. The functional properties of Mf glycated with both glucose and maltodextrin changed significantly, compared to unglycated Mf, and the conjugates of M-G were superior to $\mathrm{M}-\mathrm{M}$ in solubility and foaming properties; however, $\mathbf{M}-\mathbf{M}$ had better heat stability and emulsifying properties. This may be ascribed to the difference in molecular weight and steric hindrance of sugars. Glucose may be prone to bind with Mf, while maltodextrin, with large molecular weight and steric hindrance, has advantage of protecting proteins from heat denaturation. Thus, the differences in functional properties of $\mathbf{M}-\mathbf{M}$ and $\mathbf{M}-\mathrm{G}$ are in agreement with the results of the physicochemical properties of MRPs.

In conclusion, both glucose and maltodextrin are favorable sugar donors for glycation with Mf. These results may provide a theoretical basis for further research on glycation of Mf, such as the management of the reaction stage and choice of sugars. In addition, the improvement of functional properties resulting from glycation will contribute to better utilization of fish myofibrillar proteins in processed food.

\section{Acknowledgements}

This work was supported financially by the National Natural Science Foundation of China (No. 31301437) and Natural Science Foundation of Zhejiang (No. LQ13C200003).

\section{References}

1 Y. Yamashita, K. Arai and K. Nishita, Bulletin of the Japanese Society for the Science of Fish, 1978, 44, 485-489.

2 T. Gill, J. Chan, K. Phonchareon and A. Paulson, Food Res. Int., 1992, 25, 333-341.

3 M. Friedman, J. Agric. Food Chem., 1996, 44, 631-653. 4 J. Liu, Q. Ru and Y. Ding, Food Res. Int., 2012, 49, 170-183.

5 C. M. Oliver, L. D. Melton and R. A. Stanley, Crit. Rev. Food Sci. Nutr., 2006, 46, 337-350.

6 R. Sato, S. Katayama, T. Sawabe and H. Saeki, J. Agric. Food Chem., 2003, 51, 4376-4381.

7 H. Saeki and M. Tanabe, Fish. Sci., 1999, 65, 967-968.

8 K. Fujiwara, T. Oosawa and H. Saeki, J. Agric. Food Chem., 1998, 46, 1257-1261.

9 K. Nishimura, M. Murakoshi, S. Katayama and H. Saeki, Biosci., Biotechnol., Biochem., 2011, 75, 247-254.

10 J. Liu, X. Wang and Y. Ding, Carbohydr. Polym., 2013, 92, 484-489. 
11 H. Saeki, J. Agric. Food Chem., 1997, 45, 680-684.

12 M. Dubois, K. A. Gilles, J. K. Hamilton, P. Rebers and F. Smith, Anal. Chem., 1956, 28, 350-356.

13 H. Frister, H. Meisel and E. Schlimme, Fresenius' Z. Anal. Chem., 1988, 330, 631-633.

14 K. Nishimura, M. Murakoshi, S. Katayama and H. Saeki, Food Sci. Technol. Res., 2010, 17, 69-75.

15 K. N. Pearce and J. E. Kinsella, J. Agric. Food Chem., 1978, 26, 716-723.

16 C. C. Sánchez and J. M. R. Patino, Food Hydrocolloids, 2005, 19, 407-416.

17 E. Huff-Lonergan, T. Mitsuhashi, F. Parrish and R. M. Robson, J. Anim. Sci., 1996, 74, 779-785.

18 S. Katayama, J. Shima and H. Saeki, J. Agric. Food Chem., 2002, 50, 4327-4332.

19 R. Sato, T. Sawabe, H. Kishimura, K. Hayashi and H. Saeki, J. Agric. Food Chem., 2000, 48, 17-21.

20 I. A. Farhat, S. Orset, P. Moreau and J. M. Blanshard, J. Colloid Interface Sci., 1998, 207, 200-208.

21 J. A. Turner, L. R. Sivasundaram, M.-A. Ottenhof, I. A. Farhat, R. S. Linforth and A. J. Taylor, J. Agric. Food Chem., 2002, 50, 5406-5411.

22 C. M. Oliver, A. Kher, D. McNaughton and M. A. Augustin, J. Dairy Res., 2009, 76, 105-110.

23 F.-L. Gu, J. M. Kim, S. Abbas, X.-M. Zhang, S.-Q. Xia and Z.-X. Chen, Food Chem., 2010, 120, 505-511.

24 J. C. Cardoso, R. L. C. Albuquerque Jr, F. F. Padilha, F. O. Bittencourt, O. de Freitas, P. S. Nunes, N. L. Pereira, M. J. V. Fonseca and A. A. S. Araújo, J. Therm. Anal. Calorim., 2010, 104, 249-254.

25 J. Yongsawatdigul and B. O. Hemung, J. Food Sci., 2010, 75, C251-C257.
26 H. Saeki and K. Inoue, J. Agric. Food Chem., 1997, 45, 34193422.

27 R. Sato, T. Sawabe and H. Saeki, J. Food Sci., 2005, 70, C58C62.

28 E. Sanmartín, J. C. Arboleya, M. Villamiel and F. J. Moreno, Compr. Rev. Food Sci. Food Saf., 2009, 8, 332-344.

29 A. Kato, K. Murata and K. Kobayashi, J. Agric. Food Chem., 1988, 36, 421-425.

30 D. Christ, K. P. Takeuchi and R. L. Cunha, J. Food Sci., 2005, 70, E230-E238.

31 K.-I. Izutsu, N. Aoyagi and S. Kojima, Chem. Pharm. Bull., 2004, 52, 199-203.

32 H. Enomoto, C.-P. Li, K. Morizane, H. R. Ibrahim, Y. Sugimoto, S. Ohki, H. Ohtomo and T. Aoki, J. Agric. Food Chem., 2007, 55, 2392-2398.

33 A. Kato, T. Fujishige, N. Matsudomi and K. Kobayashi, J. Food Sci., 1985, 50, 56-58.

34 Y. Li, F. Zhong, W. Ji, W. Yokoyama, C. F. Shoemaker, S. Zhu and W. Xia, Food Hydrocolloids, 2013, 30, 53-60.

35 A. Kato, K. Minaki and K. Kobayashi, J. Agric. Food Chem., 1993, 41, 540-543.

36 B. Zhang, X. Guo, K. Zhu, W. Peng and H. Zhou, Carbohydr. Polym., 2015, 127, 168-175.

37 L. Were, N. Hettiarachchy and U. Kalapathy, J. Food Sci., 1997, 62, 821-824.

38 F. Chevalier, J.-M. Chobert, Y. Popineau, M. G. Nicolas and T. Haertlé, Int. Dairy J., 2001, 11, 145-152.

39 R. Li, N. Hettiarachchy, S. Rayaprolu, M. Davis, S. Eswaranandam, A. Jha and P. Chen, J. Food Sci. Technol., 2015, 52, 6067-6072. 